\title{
Android Based Car Parking System
}

\author{
Prof. Langote, Lonkar Prathmesh, Arfat Bagwan, Rushikesh Vayandeshkar
}

Department of Computer Engineering, MIT Polytechnic, Pune, Maharashtra, India

\section{Article Info}

Volume 7, Issue 3

Page Number: 523-525

\section{Publication Issue :}

May-June-2021

\section{Article History}

Accepted : 01 June 2021

Published : 08 June 2021

\section{ABSTRACT}

In this work, we mainly focus on designing a new smart parking system that assists drivers to find parking spaces in a specific parking district. In addition, one of the important aims is to control the traffic created while searching space for parking, this will reduce the air pollution as well as energy consummations. The main motivation for developing this project is to reduce the traffic congestion which occurs in the urban areas, which is due to the vehicles searching for parking. The increase in city traffic is one of the major effects of population growth especially in urban areas. Due to this searching for a vacant parking area during peak hour is not only time-consuming but also result in wastage of fuel. Moreover, I value recent learning about the Android Programming languages as well as seeing how powerful and dynamic they are when it comes to Application designing.

Keywords : Localization, Range Free, Survey, Wireless Sensor Network, Mobile Anchor, Vehicles

\section{INTRODUCTION}

Too many cars, too much traffic and there is no enough parking area. This is the situation which is seen in most of the metropolitan cities today. People keep on roaming on roads searching for a parking space to park their vehicles especially at peak hours of time. Our proposed system presents a smart parking system that regulates a number of vehicles to the nearest parking space at any given time based on the parking space availability. "Intelligent Parking System (IPS)" is implemented using the Operating System Android. The user requests the Parking Control Unit to check the status of available parking slots. As soon as the user request, all the available free slots are displayed to the user. If the availability of parking space is confirmed, the user can book the parking slot and proceed to pay.

The vehicle follows its path towards the starting of the parking area. The user fixes his slots by showing his confirmation details to the concerned person at Parking area. After communicating, the vehicle will further follow its path to the allocated parking slot. After successful parking the slot details are updated simultaneously in the Administrators database. Finally the time to find for an empty parking slot is minimized. The main responsibility of the Intelligent 
Parking System (IPS) is to help the user to find an area where parking is available and total number of slots free in that area. Thus our proposed methodology re.

\section{Discussion}

This project is based on android.it the main reason for doing this project is, as we see in city there is more traffic and main problem in the city is the parking.parking is most problem in the city.thats why we thought that their should be a solutopn for this parking system.then we develop a idea about that the people should quite get easy for parking oue car in less time and also it provide theb all the information about this parking system.

\section{Literature Survey}

There are several methods employed for the vehicle parking. The concept of new smart parking solves the parking problem by using mixed integer linear problem. The disabled person can park the vehicle at specially designed locations. Automatic parking and UN parking with the help of android applications.to it may switch it back to green. If any folding barriers and obstacles that emerge from and retract to the ground under a parking spot are wirelessly activated by the device on-board vehicles similar to mechanis $\mathrm{ms}$ for electronic toll systems.

\section{Features}

1. When the user choose the destination point,the system shows the user nearby parking area to the destination.

2. It also show,the parking area is full or it has some vacant space.

3 . The user can also prebook the area.

4. The system also shows even-odd area.(for.eg p1,p2)

5. It shows the user is the parking area is pubici.e free or it takes charges.

6. It also calculate the charge of the parking area according to in-out time
System Architecture

\section{SYSTEM ARCHITECTURE}

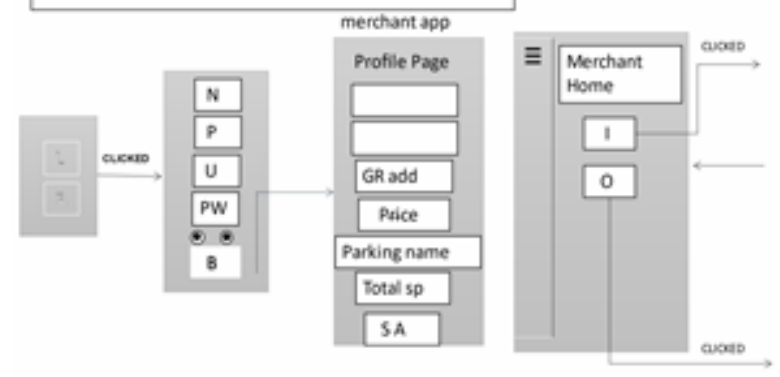

Figure 1. System Architecture

Software Specification:

- Android

- Android Developer

\section{CONCLUSION}

The conclusion is to implement a android based car parking system. As per the development the system was completely designed without any difficulty by book the parking for our car with the help of this android developer. Any time and from anywhere we can book the parking for our car and all the details were given in this mobile app. All the information for booking the parking is given there just we have to do the booking process, all required thing we have to put in that is easy way.

\section{ACKNOWLEDGEMENT}

The authors are very thankful for the best, supportive and expert guidance of Prof. Mrs. Vaishali Langote for her hard work throughout our project and also thankful to the engineering college of MAREERS'S MIT Polytechnic. 
Prof. V. B. Langote et al Int. J. Sci. Res. Comput. Sci. Eng. Inf. Technol, May-June - 2021, 7 (3) : 523-525

\section{VII.WEB REFERENCES}

[1]. https://ieeexplore.ieee.org/do cument/781969

[2]. https://ieeexplore.ieee.org/document/8932730

[3]. https://ieeexplore.ieee.org/document/6511552

\section{Cite this article as :}

Prof. Langote, Lonkar Prathmesh, Arfat Bagwan, Rushikesh Vayandeshkar "Android Based Car Parking System ", International Journal of Scientific Research in Computer Science, Engineering and Information Technology (IJSRCSEIT), ISSN : 24563307, Volume 7, Issue 3, pp. 523-525, May-June-2021. 